\title{
Antibiotic prophylaxis for urinary tract infections after removal of urinary catheter: meta-analysis
}

This Research paper by Marschall and colleagues (BMJ 2013;346:f3147, doi:10.1136/bmj.f3147) contains an error in table 1 . In the 2006 study by Brandenburg et al, the median number of days of catheterisation in the control group should have read 3 (not 33, as published).
Cite this as: BMJ 2013;347:f5325

๑ BMJ Publishing Group Ltd 2013 